\title{
Foreword by Rt Hon Helen Clark ${ }^{1}$
}

New Zealand's management of the COVID-19 pandemic is of global interest. The country's approach of zero-tolerance towards transmission of the disease in the community has enjoyed wide public support and, notwithstanding the small number of occasions when the virus has spread beyond the border since the end of the major national lockdown from March to May, has been remarkably successful.

This book, which offers management perspectives on the handling of the crisis in New Zealand, is very timely, not only because many countries are still battling major outbreaks of COVID-19 and are looking for examples of what has worked elsewhere, but also because there will be a need to maintain vigilance against COVID-19 for the long term. The disease looks set at some point to move from being pandemic in nature to being endemic. That means we cannot relax our guard. International interest will be as strong in how New Zealand plans to keep the disease at bay for the foreseeable future as it has been in its success in curbing transmission to date. Continued public buy-in to ongoing public health measures is essential.

New Zealand's success has been scoffed at in some circles because of the protection which our geography provides us. Yet, we could all too easily have blown that advantage with an economy-first, rather than a health-first approach. A key factor in New Zealand's approach was to put people's health first, and to recognise that having a fearful, insecure public traumatised by the loss of family, friends, and colleagues would be destructive of the well-being of both the society and the economy.

While the country has taken an economic hit, with the international tourism and education-related sectors suffering disproportionately, the availability of social protection, retraining and job placement services, and business support schemes have all helped to cushion the blows. As there is unlikely to be a return to the status quo ante, a repositioning of the economy and workforce to enable it to thrive in the new normal will be vital.

The New Zealand approach was also based on accepting the best scientific and public health advice on how to manage a pandemic. This too distinguishes it from that of a range of countries where the disease was downplayed and health systems quickly became overwhelmed. It is not possible to hospitalise or treat one's way out of a pandemic: transmission just has to be curbed. In many respects there is nothing new about how to do that. Capacities have to be 
built and sustained for testing, tracing, quarantine, and consistent messaging and engagement with the public around the need for physical distancing, mask wearing, and hygiene. Many countries are still struggling to develop those capacities.

The rapid development of vaccines is a welcome development, but their rollout is not a panacea. The next campaign must be to achieve a high level of acceptance of vaccination in the community. Then, much continues to be unknown about the impact and evolution of COVID-19. Variants of it which have already emerged are causing justified concern. It remains to be seen how effective current vaccinations will be as populations encounter new variants, and if and whether there will need to be periodic revaccination. Continued research and development to ensure ongoing protection through immunisations will be vital, as it will be for innovations in testing and diagnosis and treatments.

Central to building resilient health systems, societies, and economies is being prepared to review how these have responded to a severe shock. The World Health Assembly mandated such a review of the internationally co-ordinated response to COVID-19, with a view to distilling lessons learned and identifying areas for improvement. Every country should be prepared to do the same, regardless of its success or otherwise in managing the crisis. Being prepared to reflect and learn, and committing to continual improvement equips countries to do better next time. This publication is an important contribution to such a review, and its chapters written from a range of perspectives deserve serious consideration.

29 January 2021

\section{NOTE}

1. Former Prime Minister of New Zealand and former UNDP Administrator. Co-Chair of The Independent Panel for Pandemic Preparedness and Response. 